\title{
TRANSMISSION ELECTRON MISCROSCOPY OF SIMULATED DWPF HIGH LEVEL NUCLEAR WASTE GLASSES FOLLOWING GAMMA IRRADIATION
}

by

J. C. Marra

Westinghouse Savannah River Company

Savannah River Site

Alken, South Carolina 29808

N.E. Bibler

J. R. Harbour

M. H. Tosten

This paper was prepared in connection with work done under the above contract number with the U.S.

Department of Energy. By acceptance of this paper, the publisher and/or recipient acknowledges the U.S. Government's right to retain a nonexclusive, royalty-free license in and to any copyright covering this paper, along with the right to reproduce and to authorize others to reproduce all or part of the copyrighted paper.

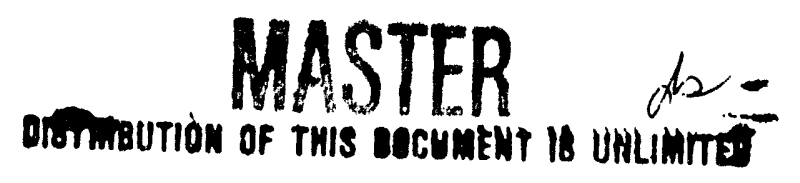




\section{DISCLAIMER}

This report was prepared as an account of work sponsored by an ageacy of the United States Government. Neither the United States Government nor any agency thereof, nor any of their employees. makes any warranty, express or implied. or assumes any legal liability or responsibility for the accuracy. completeness, or usefulaess of any information. apparatus, product, or process disclosed, or represents that its use would not infringe privately owned rights. Reference herein to any specific commercial product, process, or service by trade name. trademark. manufacturer, or otherwise does not necessarily constitute or imply its endorsement, recommendation, or favoring by the United States Governmeat or any agency thereof. The views and opinions of authors expressed berein do not necessarily state or reflect those of the United States Government or any ageacy thereof.

This report has been reproduced directly from the best available copy.

Available to DOE and DOE contractors from the Office of Scientific and Technical Information. P. O. Box 62. Oak Ridge. TN 37831: prices available from (615) $576-8401$.

Available to the public from the National Technical Information Service, U. S. Deparmeat of Commerce, 5285 Port Royal Rd., Springfield. VA 22161 
TRANSMISSION ELECTRON MICROSCOPY OF SIMULATED DWPF HIGH LEVEL NUCLEAR WASTE GLASSES FOLLOWING GAMMA IRRADIATION

\author{
J. C. Marra, N. E. Bibler, J. R. Harbour and M. H. Tosten \\ Westinghouse Savannah River Company \\ Savannah River Technology Center \\ P. O. Box 616 \\ Aiken, SC 29808
}

\begin{abstract}
Thermal analysis testing revealed slight weight changes, which were a function of gamma irradiation, in a highly reduced DWPF simulated waste glass. Transmission electron microscopy (TEM) was performed on these glasses to see if the weight change corresponded to microstructural variations. TEM analyses showed that no microstructural changes were attributable to gamma irradiation. Exposure of the samples to the electron beam in the TEM did result in some changes in the glass microstructures in some cases. These changes were likely due to localized heating of the glass due to interactions with the transmitted electrons.
\end{abstract}

\title{
INTRODUCTION
}

In the near future the Defense Waste Processing Facility (DWPF) at the Savannah River Site (SRS) will begin stabilizing high-level radioactive waste using borosilicate glass. The molten waste glass will be poured into stainless steel canisters which, after cooling, will be welded shut to produce the canistered waste forms. Following interim storage at SRS, the glass-filled canisters will be shipped to an appropriate geologic repository for final disposal. .As a result of radioactive decay in the waste, the glasses will absorb large doses of alpha, beta, gamma, neutron, and alpha recoil radiation which raises issues regarding the stability of the canistered waste forms.

The Department of Energy (DOE) has issued the Waste Acceptance Product Specifications (WAPS) which must be satisfied prior to shipment of the canistered waste forms to a repository [1]. One of the specifications requires the identification of any volatiles produced as a result of accidentally heating the waste glass to the glass transition temperature $(\mathrm{Tg})$. The rationale for volatile identification is to ensure that the volatile species will not compromise the integrity of the canister and are not foreign materials as defined by the WAPS.

Thermogravimetric analysis (TGA) of irradiated and unirradiated glass samples revealed slight weight changes in a highly reduced simulated waste glass following 
gamma irradiation [2]. In the TGA results, small weight losses were observed concomitantly in regions with overall larger weight increases (Figure 1). The extent of volatility (i.e. weight loss) was determined to be a function of gamma irradiation fluence. This volatility will not affect the integrity of the canistered waste form since only oxidized glasses will be made in the DWPF.

It has been reported that gamma irradiation can cause microstructural changes in waste glasses due to a radiolytic effect [3-5]. This change in microstructure was presumed to result from the formation of oxygen microbubbles due to radiolytic decomposition of oxides and reduction of associated cations [5]. It was postulated that the bubble formation could decrease the durability of the glass due to an increase in surface area [5]. Results contradicting these findings, on similar waste glass formulations, have also been reported [6]. Transmission electron microscopy (TEM) examination of gamma irradiated glass samples indicated no change in microstructure attributable to gamma irradiation [6]. However, severe damage to the glasses (i.e. bubble formation and melting) could be induced by the electron beam in the microscope. Similar electron beam damage in glasses has been reported elsewhere [7-8].

This paper describes TEM analyses on unirradiated and gamma irradiated highly reduced, simulated waste glasses. The purpose of these experiments was to identify microstructural changes in the glass which might explain the slight weight changes observed in the TGA experiments and to assess microstructural variations which might affect glass durability as proposed in the work by Denatale and Howitt [5].

\section{EXPERIMENTAL PROCEDURE}

\section{Glass Composition}

The simulated nuclear waste glass used in this study was SRS glass SGM 7-8. The composition is similar to borosilicate formulations projected for the DWPF except for an extremely high redox ratio [9]. The redox level of the glass is reflected by the $\mathrm{Fe}^{2+} /\left(\mathrm{Fe}^{2+}+\mathrm{Fe}^{3+}\right)$ ratio and is limited to less than or equal to 0.1 by the WAPS. In this highly reduced glass, this ratio was 0.63 . This glass composition was examined in this effort due to the unusual behavior observed in the TGA experiments. It should be noted that samples more typical of the redox ratio specified for the DWPF waste glass were also analyzed using TEM. The results were similar to those described in this paper and for brevity will not be discussed further.

\section{Sample Preparation}

Preparation of thin sections of inorganic materials suitable for observation in the TEM is a consictent problem. Several techniques are available, however, each involves material removal which may affect the nature of the observed sample. For this reason, a number of specimen preparation techniques were employed to minimize these effects and to attempt to identify any induced artifacts. In one method, a crush and disperse method was used on both bulk irradiated and pre-crushed irradiated glasses. In this 
technique, shards of glass are dispersed in acetone and deposited on a carbon covered copper grid for examination. The second method involved ion-milling glass samples until perforation. Ion-milling was accomplished using $\mathrm{Ar}^{+}$ions with an acceleration voltage of $6 \mathrm{keV}$. To examine any effect the ion-milling process might have on the nature of the samples, several different sample preparation conditions were examined. These included: sectioning and thinning from bulk unirradiated (as-received) and gamma irradiated glasses followed by ion-milling; sectioning, thinning, gamma irradiation followed by final ion milling; sectioning, thinning, ion-milling, and gamma irradiation of milled specimens; and sectioning thinning, ion-milling, e- irradiation (via examination in TEM) and gamma irradiation. A summary of the sample conditions is shown in Table I.

Irradiation Procedure

Irradiations were performed in a Co-60 gamma ray source. The powder samples and bulk glass were irradiated to doses of $5 \times 10^{8}$ rads and $5 \times 10^{9}$ rads using nominal dose rates of $5 \times 10^{4} \mathrm{rads} / \mathrm{hr}$. The thinned and ion-milled samples were irradiated to doses of $5 \times 10^{8}$ rads using equivalent dose rates.

Two sets of thinned and ion-milled specimens were exposed to the gamma source. One set was placed in vials in the presence of air, while the other set was sealed in glass ampoules under vacuum.

\section{Transmission Electron Microscopy}

Prior to examination in the electron microscope the ion-milled samples were carbon coated (to prevent sample "charging") using a high vacuum $\left(1 \times 10^{-5}\right.$ torr) evaporator. This coating process typically results in carbon thicknesses of $100-200 \AA$. The glass shards dispersed on the copper grids did not require a conductive coating which resolves any doubt about the carbon film masking small microstructural features. A Philips EM400T transmission electron microscope was used for specimen examination. A $120 \mathrm{keV}$ electron beam was selected and a low emission current was used. The low emission current was observed to decrease the amount of electron beam damage to the glass specimens.

\section{RESULTS AND DISCUSSION}

\section{Weight Changes Observed in TGA}

A heating profile was utilized in the thermal analysis experiments to highlight changes in the glass occurring near the glass transition temperature $\left(\mathrm{T}_{\mathrm{g}} \approx 450-500{ }^{\circ} \mathrm{C}\right)$ [2]. Glass powder was heated to $450{ }^{\circ} \mathrm{C}$ at rate of $10^{\circ} \mathrm{C} /$ minute, held at $450{ }^{\circ} \mathrm{C}$ for 10 minutes, heated to $500{ }^{\circ} \mathrm{C}$ at $0.5^{\circ} \mathrm{C} /$ minute, held at $500^{\circ} \mathrm{C}$ for 10 minutes and cooled using the reverse of the heating profile. The results (Figure 1) indicate an overall weight increase as the sample is heated in the presence of air. However, two regions of slight weight loss were observed to occur concomitantly with the weight gain at 
approximately $350^{\circ} \mathrm{C}$ and $475^{\circ} \mathrm{C}$. These effects were compounded with increasing irradiation dose.

\section{TEM Observations}

The TEM results indicated that gamma irradiation did not cause microstructural changes* in any of the samples examined. Thus, microstructural variations do not account for changes observed in the thermal analysis results. Furthermore, gamma irradiation did not cause any observable microstructural changes which may compromise the durability of the waste glass. The following discussion of the TEM results provides support for these claims and provides several additional observations regarding electron beam interaction with the glass.

\section{Powder Specimens}

Figures 2 and 3 show micrographs of unirradiated glass and gamma irradiated ( $5 \times 10^{9}$ rads) glass taken immediately after focus and following extended exposure to the electron beam. No evidence of bubbles or microstructural variations could be attributed to gamma irradiation. A "mottled" microstructure resulted following extended exposure to the electron beam. The mottled appearance may be due to phase separation in the glass via a spinodal decomposition mechanism. Additionally, distinct bubbles formed in the irradiated powder (Figure 3b) sample following an exposure of approximately 8 minutes. Previous work by Bibler, et al. reported that an increased gamma ray fluence caused glasses to be more susceptible to the electron beam in the TEM [6]. This behavior also appeared to apply to the present efforts, however, the effect of sample thickness (described below) may complicate this observation.

In many cases glass particles exposed to the electron beam softened and melted. When this occurred, volatile species were ejected from the glass and condensed on the carbon grid. Electron dispersive spectroscopy (EDS) revealed that these species were alkalis ( $\mathrm{K}$ or $\mathrm{Na}$ ) indicating they were the result of the decomposition of alkali constituents in the glass. The resulting "spheroidized" glass contained many crystalline species, likely spinel compounds.

\section{Ion-milled Specimens}

The micrographs of the unirradiated ion-mill samples illustrate the increase of observable thîn area afforded by this specimen preparation technique (Figure 4). A generally featureless microstructure is evident in both micrographs. The small dark spots are undoubtedly a micro-crystalline phase in the glass. Similar species have been observed in other waste glass compositions. Neither the elemental composition nor the crystalline phase could be identified, however, due to the small size and volume fraction of the phase. It is interesting to note that little coarsening or change in the

* The TEM has approximately $1 \mathrm{~nm}(10 \AA)$ resolution, so no microstructural changes down to $1 \mathrm{~nm}$ were observed. 
microstructure occurred with extended electron beam exposure. This indicates that the electron beam interaction with the sample is apparently thickness related since the thicker glass shards were much more susceptible to electron beam damage. Since the electrons "interact" with the glass during transmission through the sample, it follows that in thicker samples more interactions will occur. The electron/glass interactions generate heat within the glass structure, so it is not surprising to see the structural damage, melting and gross crystallization in the shard samples.

The intensity of the electron beam also influences the degree of interaction of the beam with the glass. Under conditions of an increased beam current and smaller beam size, damage to the glass microstructure was observed even in the ion-milled samples (Figure 5).

These experiments demonstrated that gamma irradiation caused no observable changes to the glass microstructure. Figure 6 shows micrographs of what can be considered the worst-case sample conditions (i.e. sectioned, thinned, ion-milled, e- beam exposure (pre-examined), and gamma irradiation). This was the same sample shown in Figure 4. That is, when this sample was "pre-examined" the results were used as sample "IM-U: unirradiated, ion-milled". Although it is almost impossible to ensure the observation of the same areas, the use of this sample provided the direct comparison of the same glass before and after irradiation. The lack of microstructural variations as compared to Figure 4 is quite evident both before and after electron beam exposures. The micro-crystalline species are still evident, however, the size and number density were generally unchanged.

\section{CONCLUSIONS}

- Gamma irradiation caused no observable microstructural changes in any of the samples examined.

- Thicker samples appeared to be more susceptible to electron beam damage due to a sample heating effect.

- Damage to the glass spécimens was directly related to the intensity of the electron beam.

- Alkali species were ejected from the glass when the electron beam caused melting of the glass fragments and crystal formation in the remaining glass was observed. 


\section{REFERENCES}

1. Office of Environmental Restoration and Waste Management, Waste Acceptance Product Specifications for Vitrified High-Level Waste Forms, February, 1993.

2. J. R. Harbour, J. C. Marra and N. E. Bibler, "The Effect of Gamma Irradiation on the Volatility and Redox State of Simulated DWPF High-Level Nuclear Waste Glasses", High Level Radioactive Waste Management, Proceedings of the Fourth Annual International Conference, Volume 2, American Nuclear Society, La Grange Park, IL and American Society of Civil Engineers, New York, NY p 1735, 1993.

3. J. P. Heuer and D. G. Howitt, "Oxygen Butble Formation in Nuclear Waste Glasses by Gamma Irradiation", Microbeam Analysis, Edited by R. H. Geiss, San Francisco Press, p 225, 1987.

4. J. F. Denatale and D. G. Howitt, "The Gamma-Irradiation of Nuclear Waste Glasses", Radiation Effects '91, p 89, 1985.

5. J. F. Denatale and D. G. Howitt, "A Mechanism for Radiation Damage in Silicate Glasses", Nuclear Instruments and Methods in Physics Research, Vol. B1, p 489, 1984.

6. N. E. Bibler, M. H. Tosten and D. C. Beam, "Recent Results on the Effect of Gamma Radiation on th . Durability and Microstructure of DWPF Glass", High Level Radioactive W: Management, Proceedings of the Fourth Annual International Confere ice, Volume 2, American Nuclear Society, La Grange Park, IL and American Society of Civil Engineers, New York, NY p 1103, 1990.

7. S. Sato, K. Asakura and H. Furuya, "Microstructure of High-Level Radioactive Waste Glass Heavily Irradiated in a High-Voltage Electron Microscope", Nuclear Chemical Waste Management, 4, p 147, 1983.

8. S. Sato, H Furuya, K. Asakura, K. Ohta and T. Tamai, "Radiation Effect of Simulated Waste Glass Irradiated with Ion, Electron, and Gamma Rays", Nuclear Instrument and Methods in Physics Research, Vol. B1, p 534, 1984.

9. J. R. Harbour, "Volatility of Simulated High-Level Nuclear Waste Glass by Thermogravimetric Analysis", Journal of the American Ceramic Society, 75, p 507, 1992. 
Table I

Sample Conditions for TEM Ánalysis

\begin{tabular}{|c|c|c|c|}
\hline $\begin{array}{l}\text { Sample } \\
\text { Denotation }\end{array}$ & Description & $\begin{array}{l}\text { Pre-examined } \\
\text { (e- radiation) }\end{array}$ & $\begin{array}{l}\gamma \text {-radiation } \\
\text { Condition }\end{array}$ \\
\hline PWDR-U & Unirradiated glass powder & No & None \\
\hline PWDR-I8 & Irradiated as powder & No & $5 \times 10^{8}, \mathrm{Air}$ \\
\hline PWDR-I9 & Irradiated as powder & No & $5 \times 10^{9}$, Air \\
\hline PC-PWDR & Irradiated piece, crushed & No & $5 \times 10^{9}$, Air \\
\hline PC-IM & Irradiated piece, ion-milled & No & $5 \times 10^{9}$, Air \\
\hline IM-U & Unirradiated, ion-milled & No & None \\
\hline IM-I8A & Ion-milled & No & $5 \times 10^{8}$, Air \\
\hline IM-I8V & Ion-milled & No & $5 \times 10^{8}, \mathrm{Vac}$ \\
\hline IM-I8Ae & Ion-milled & Yes & $5 \times 10^{8}$, Air \\
\hline IM-I8Ve & Ion-milled & Yes & $5 \times 10^{8}, \mathrm{Vac}$ \\
\hline THN-I8A & Thinned, ion milled after $\gamma$ & No & $5 \times 10^{8}$, Air \\
\hline THN-I8V & Thinned, ion-milled after $\gamma$ & No & $5 \times 10^{8}, \mathrm{Vac}$ \\
\hline
\end{tabular}




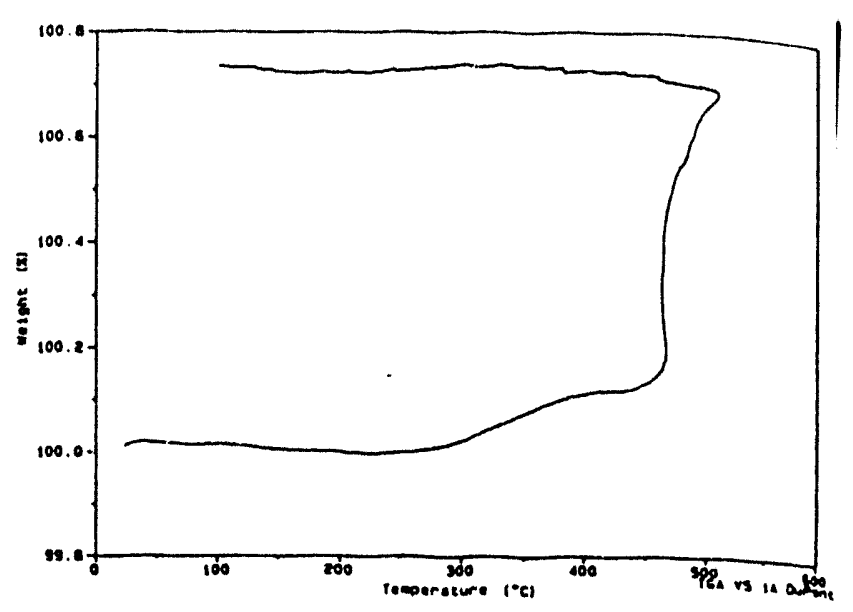

(a)

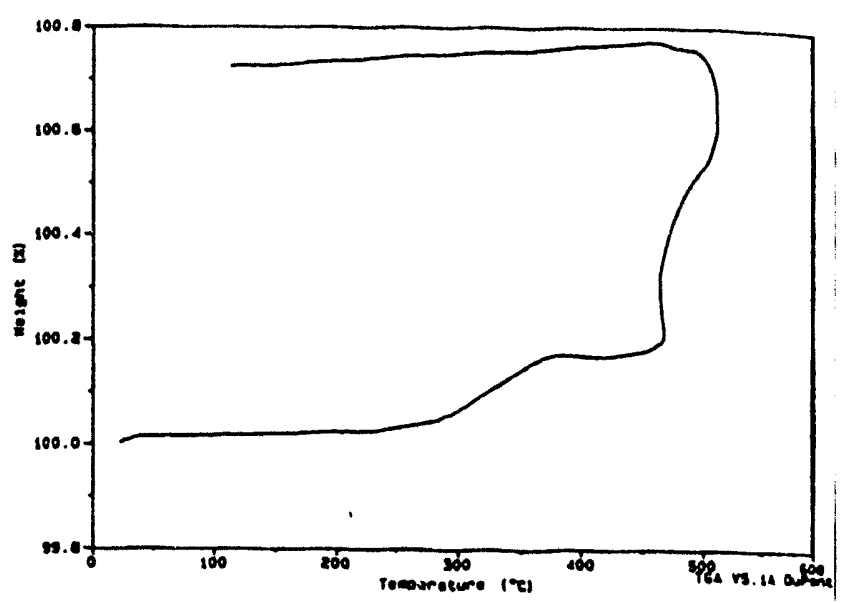

(b)

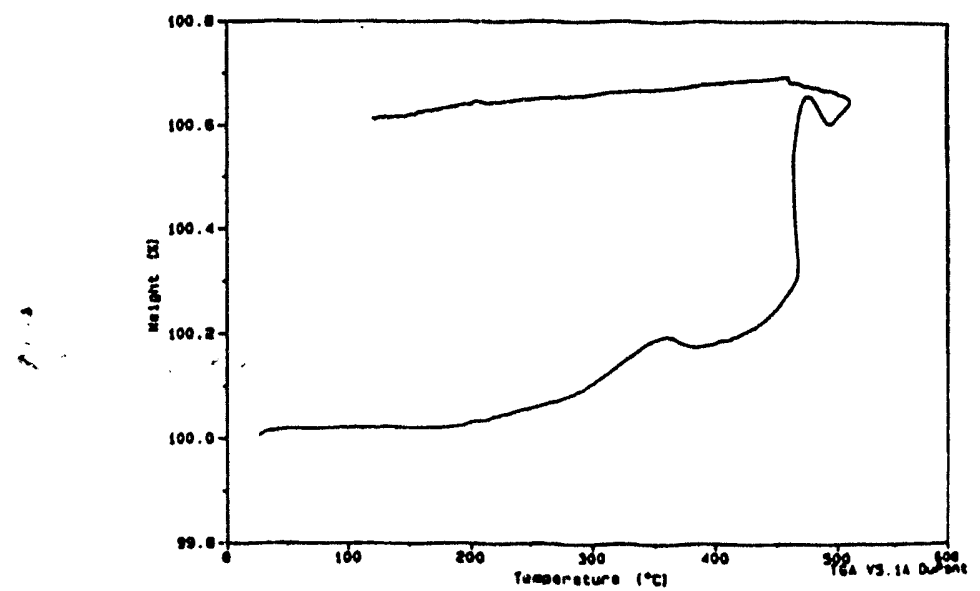

(c)

Figure 1. TGA curves for SGM 7-8 glass powder (a) before gamma irradiation, (b) after $5 \times 10^{8}$ rads gamma irradiation, (c) after $5 \times 10^{9}$ rads gamma irradiation. 

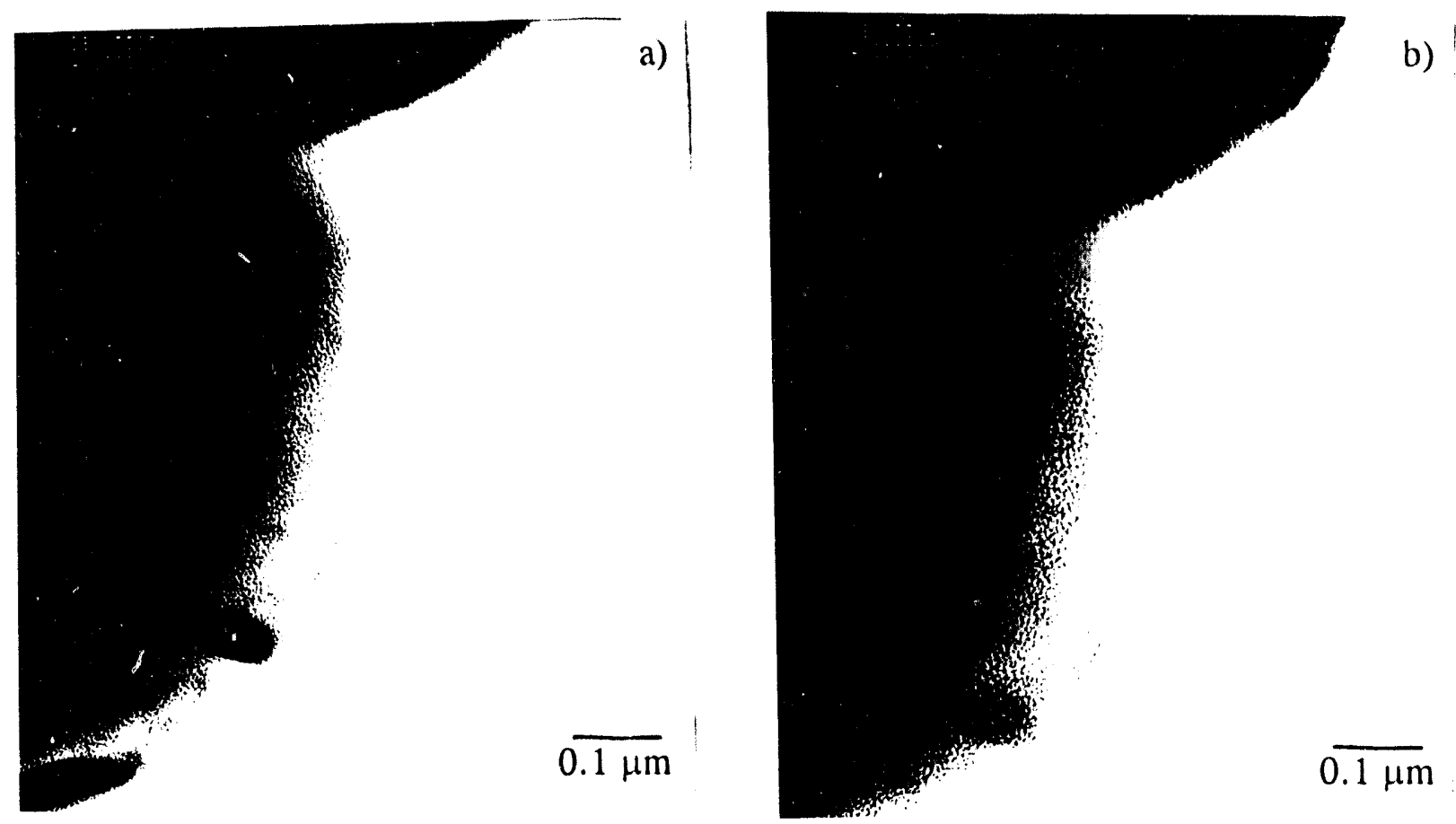

Figure 2. SGM 7-8 glass shards before gamma irradiation (sample PWDR-U)

a) immediately after focus, b) following 6 minutes electron beam exposure.
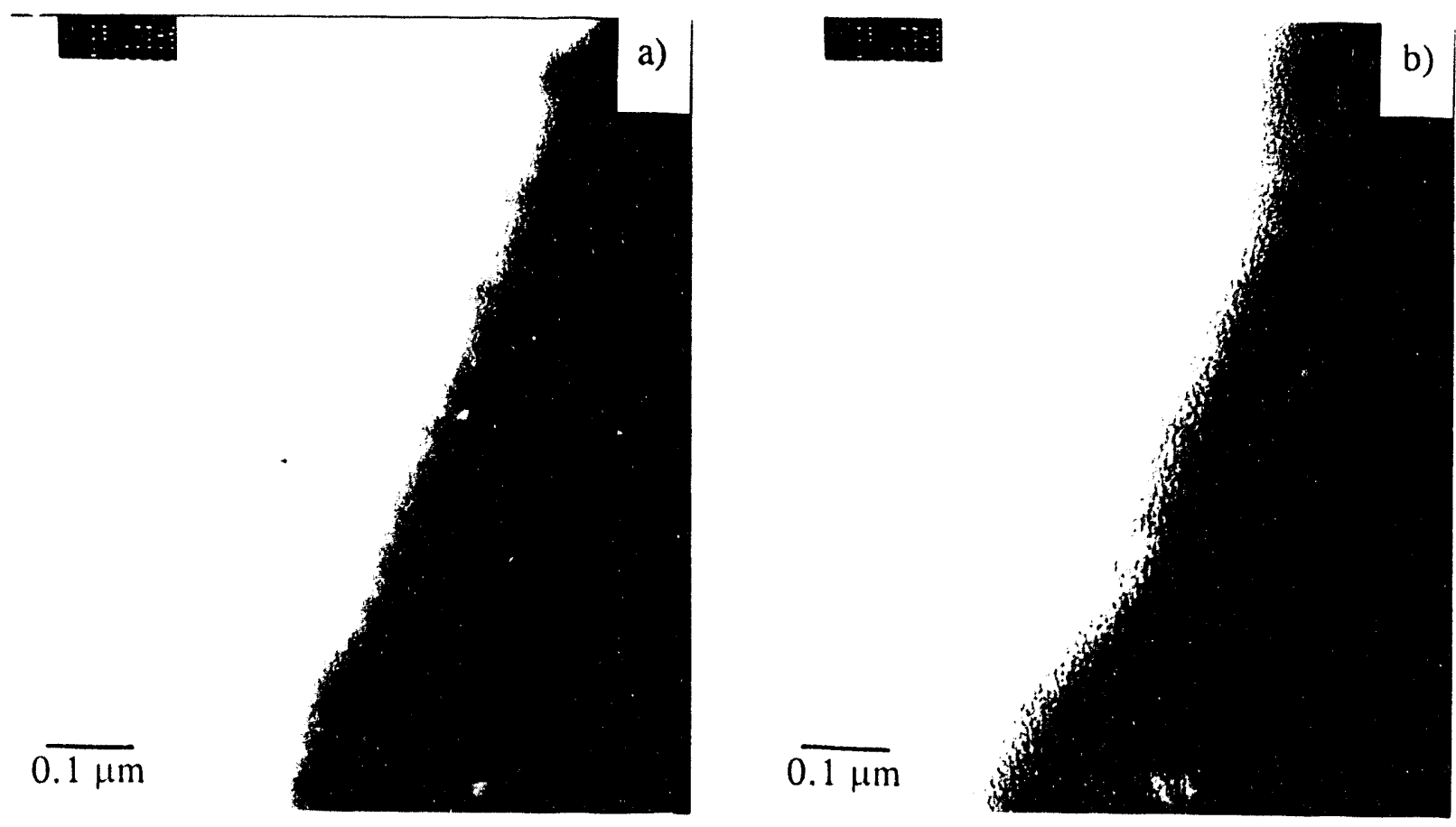

Figure 3. SGM 7-8 glass shards following $5 \times 10^{9}$ gamma irradiation (sample PWDR-19) a) immediately after focus, b) following -8 minutes electron beam exposure. 

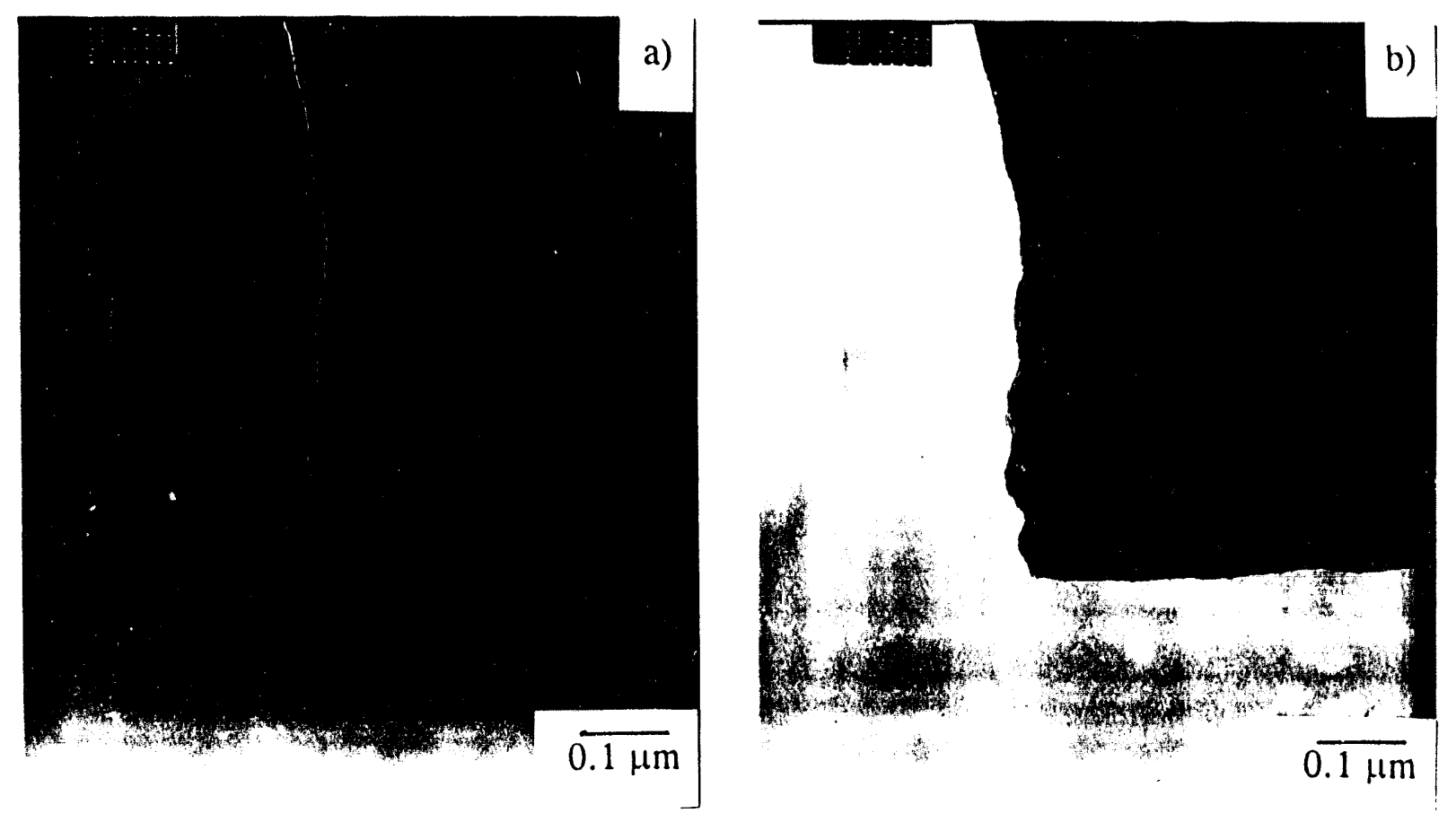

Figure 4. SGM 7-8 ion-milled glass before gamma irradiation (sample IM-U) a) immediately after focus, b) following $\sim 10$ minutes electron beam exposure.

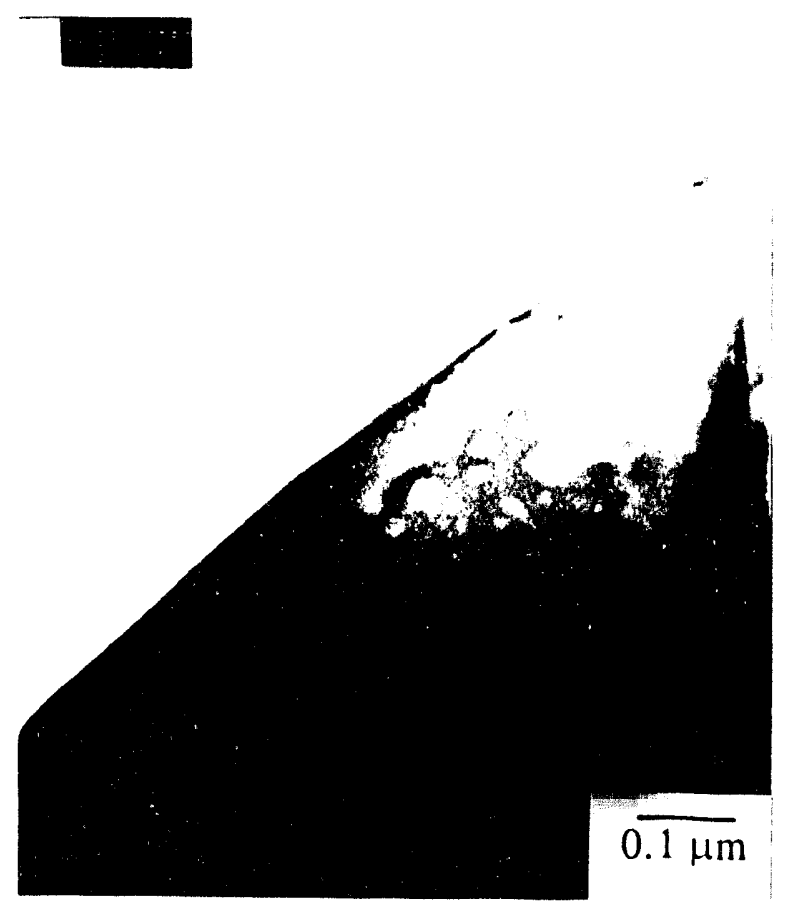

Figure 5. SGM 7-8 ion-milled glass intentionally damaged by intense electron be.ım. 

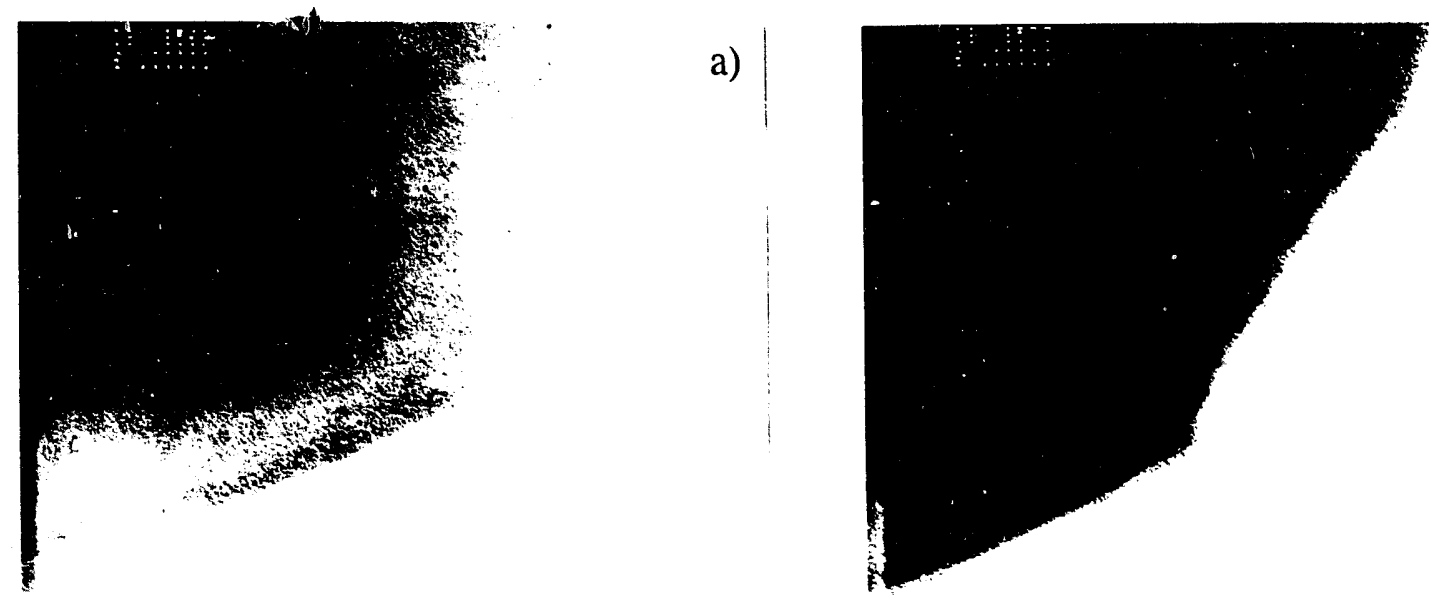

b)

$$
\overline{0.1 \mu \mathrm{m}}
$$

$\overline{0.1 \mu \mathrm{m}}$

Figure 6. SGM 7-8 ion-milled glass, pre-examined and gamma irradiated to $5 \times 10^{8}$ rads (sample IM-IAe) a) immediately after focus, b) following $\sim 10$ minutes electron beam exposure. 

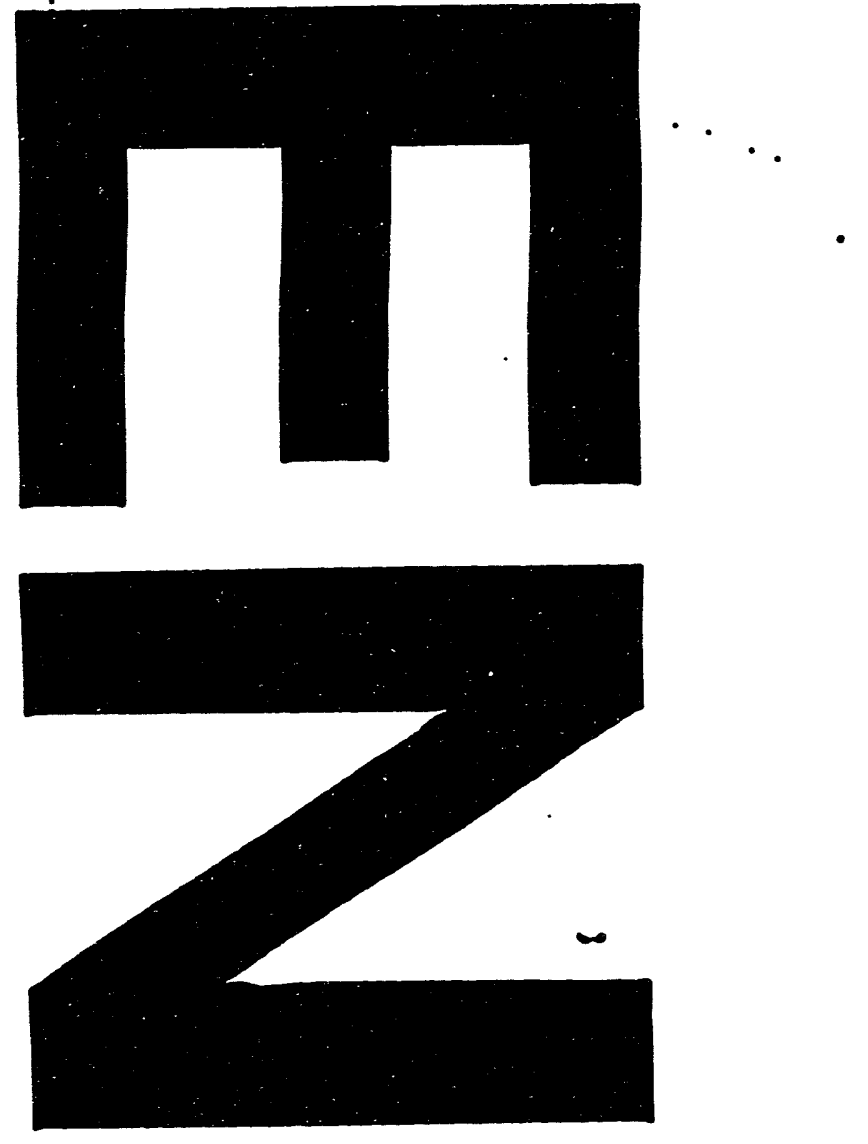

er
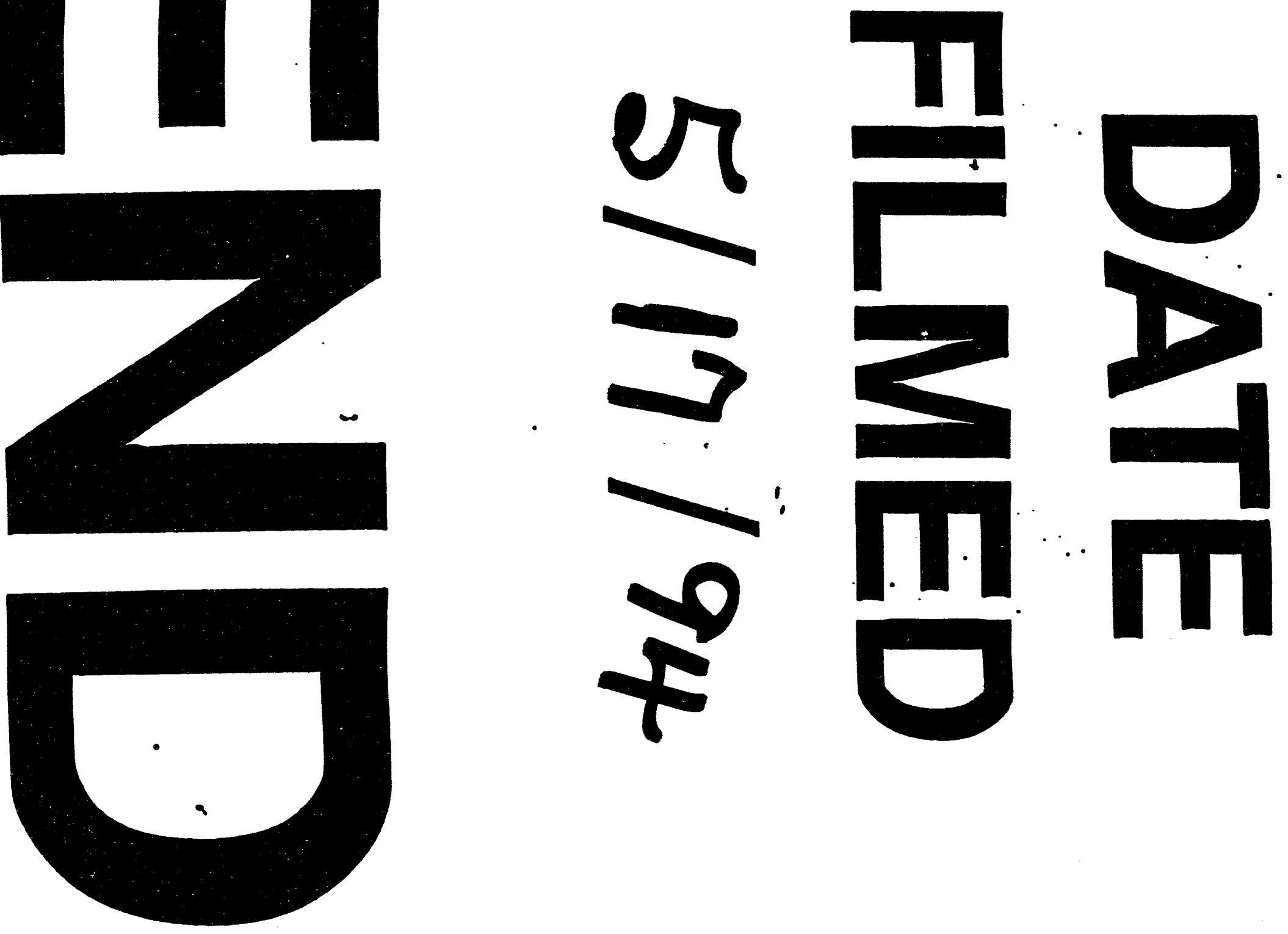
